\title{
MEMÓRIA PARA A CIÊNCIA DA INFORMAÇÃO: UM TRABALHO INTERDISCIPLINAR
}

\author{
Felipe Caldonazzo de Almeida Perreira (Biblioteconomia - UEL) \\ Jucenir da Silva Serafim (Biblioteconomia - UEL) \\ Profa. Dra. Letícia Gorri Molina (Orientadora)
}

\section{RESUMO}

A Memória é um instrumento que tem uma importante função para a sociedade, visto que ela é capaz de acessar o passado, podendo ser tanto uma prova jurídica quanto um instrumento de legitimação cultural. Por isso a memória é um objeto de estudo em diferentes áreas do conhecimento, como por exemplo, História, Psicologia, Filosofia e Ciência da Informação, permitindo uma abordagem interdisciplinar. Pelo motivo da memória fazer parte de tantos ramos do conhecimento, é imprescindível demarcá-la dentro da área da Ciência da Informação, permitindo assim que seja estudada sua função informacional dentro das Unidades de Informação, como: Arquivos, Museus e Bibliotecas, sendo este o objetivo do presente trabalho, que conduziu uma investigação bibliográfica quanto ao assunto. Revelando, preliminarmente, que as Unidades de Informação são responsáveis pela guarda de documentos e objetos informacionais, porém também assumem outra função, a de permitir o acesso, a circulação e a disseminação de material informacional, como aponta Smit (2003). A discussão que o trabalho apresenta tem o intuito de demonstrar a importância da memória nas Unidades de Informação.

Palavras-chave: Memória, Unidades de Informação, Ciência da Informação.

\section{INTRODUÇÃO}

As Unidades de Informação têm uma função que vai além da guarda dos materiais de informação, acompanhando o próprio desenvolvimento da Ciência da Informação, buscando superar o paradigma custodial. Desta forma podemos afirmar que tanto as Unidades de Informação quanto a Ciência da Informação desenvolveram uma abordagem pós-custodial.

O paradigma pós-custodial se preocupa com a disseminação da informação, por isso concordamos com Murguia, quando defende que esses lugares de memória têm "(...) uma função informacional, no sentido de lembrar os acontecimentos, pessoas e lugares que realmente existiram e cujas provas podemos encontrar nesses lugares." (MURGUIA, 2010, p. 8)

Portanto, as Unidades de Informação desenvolvem uma função de resgate da memória, ou de recuperação de informação (memória), e, para tal, necessitam de outras áreas de conhecimento e pesquisa, cabendo salientar as contribuições da Ciência da Computação, das Ciências Humanas, como Filosofia, Sociologia e, principalmente, História.

O presente artigo pretende mostrar a função informacional da memória no contexto das Unidades de Informação, isto é, bibliotecas, museus e arquivos. Estes 


\section{SEMINÁRIO DE PESQUISA EM CIÊNCIAS HUMANAS - SEPECH \\ Humanidades, Estado e desafios didático-científicos \\ Londrina, 27 a 29 de julho de 2016}

locais funcionam como repositório das informações da sociedade, seu histórico, suas produções e, por extensão, um dos lugares de memória, segundo Nora (1993). Para tal, é imprescindível uma abordagem interdisciplinar do tema.

Para tanto, foi utilizado o método de pesquisa bibliográfica para a realização do trabalho, por meio de pesquisas em artigos de periódicos e livros. Os termos utilizados foram: memória, Ciência da Informação, Unidades de Informação.

\section{ABORDAGEM INTERDISCIPLINAR E MEMÓRIA}

Contemporaneamente vem se enfrentando a questão do racionamento do conhecimento, isto é, a especialização científica, que faz com que o conhecimento seja restrito à uma área. Isto pode acarretar outros problemas, como por exemplo, a falta de diálogo entre as diferentes áreas do conhecimento, assim como as várias dimensões de pesquisa de uma só ciência. Para que uma ciência e suas teorias se fortaleçam, é essencial o diálogo com outras ciências. Pode-se dizer que desta necessidade nasce o conceito de interdisciplinaridade.

A necessidade de um conceito de interdisciplinaridade, assim como ele próprio é recente, foi cunhado em meados do século XX. De acordo com Pombo (2003), ele tem ligação direta com grandes ramos do saber como, por exemplo, a História, a Biologia, Filosofia e Psicologia; assim como, com as disciplinas curriculares. Desta forma, este conceito se relaciona com o cotidiano do homem, que pode utilizá-lo para transformar o meio em que vive. Isto é, o conceito de interdisciplinaridade se desenvolve epistemologicamente e é capaz de aperfeiçoar as tecnologias graças às necessidades educacionais e do trabalho. Porque o homem tende a procurar por formas por meio de uma relação interdisciplinar com seu meio ambiente, de se apropriar da natureza para utilizá-la a seu favor; seja para verificar, conhecer, analisar algo para poder compreender, transformar e fazer uso dos recursos para a melhoria da vida humana.

Pombo (2003) aponta que a interdisciplinaridade faz parte de uma família, que conta com a pluridisciplinaridade e transdiciplinariedade. Elas devem ser consideradas em um continuum que se inicia na coordenação (paralelismo pluridisciplinar), combinação (convergência interdisciplinar) e fusão (unificação transdisciplinar). Assim sendo, a interdisciplinaridade procura encontrar pontos de convergência entre as disciplinas, pois está no meio do processo que leva a fusão das disciplinas em busca da criação de uma nova disciplina.

Saracevic (1995) descreve a Ciência da Informação como uma área interdisciplinar por natureza; e por se tratar de uma ciência jovem, ela tende a buscar conhecimentos em teóricos de outras ciências, que contribuam tanto para ela, quanto para as áreas as quais ela se comunica. O diálogo entre a Ciência da Informação e outras ciências ocorre porque a interdisciplinaridade, ou seja, o ponto de convergência entre elas é a informação. Ela pode ser encontrada em Unidades de Informação como memória.

No texto Information as thing, Buckland (1991), apresenta a informação como tangível, o que inclui textos, documentos e objetos; porque têm a qualidade de conhecimento comunicado. Por isto, aqui a informação pode ser classificada como tangível e por isto pode ser tratada nas Unidades de Informação: as bibliotecas que tratam os livros, os objetos pelos museus e os documentos administrativos pelos 


\section{SEMINÁRIO DE PESQUISA EM CIÊNCIAS HUMANAS - SEPECH \\ Humanidades, Estado e desafios didático-científicos \\ Londrina, 27 a 29 de julho de 2016}

arquivos. À vista do que é mantido pelas Unidades de Informação, pode-se dizer que a informação, enquanto um documento é traduzida em memória histórica, administrativa ou epistemológica que pode ser facilmente recuperável.

Porém, antes de tratar a memória como uma informação, um recurso informacional, é preciso resgatar o histórico de como a memória foi trabalhada ao longo do tempo e pode-se perceber que o estudo sobre a memória tem, em sua origem, uma forte carga filosófica. Pensadores como Sócrates e Platão utilizaram esse conceito como forma de escapar ao esquecimento ou recorrendo aos mitos (HOLANDA, 2011), que também mostrou que os estudos sobre memória fazem parte de diversos ramos do conhecimento, como em História Social, Sociologia, Psicologia por exemplo. Assim, ao se utilizar o conceito de memória, é preciso um cuidado com a definição a ser utilizada e, principalmente, aquela que se encaixa aos trabalhos dos cientistas da informação.

Diversos autores mostram as diferentes formas que a memória pode assumir, como memória individual, coletiva, social, virtual, memória natural, artificial etc (SILVA e SILVA, 2005). Assim, resgatando uma conceituação de Le Goff,

a memória é a propriedade de conservar certas informações, propriedade que se refere a um conjunto de funções psíquicas que permite ao indivíduo atualizar impressões ou informações passadas, ou reinterpretadas como passadas. (SILVA e SILVA, 2009, p. 275)

A História é de grande utilidade para os cientistas da informação, visto que ela trabalha com conceitos úteis à Ciência da Informação, como em estudos sobre tradição, história social e memória coletiva. Cabendo salientar a diferenciação que Pierre Nora faz de história e memória, assim: "A memória é a vida, sempre carregada por grupos vivos e, nesse sentindo, ela está em permanente evolução, aberta a dialética da lembrança e do esquecimento [...].” (NORA, p. 9, 1993)

Memória tem uma ligação orgânica com a sociedade, com o grupo a qual pertence, remete ao mito, com sua tradição oral, se modificando cada vez que era contado, onde o lembrar e o esquecer tornavam os mitos e memórias vivos e dinâmicos. Já "a história é a reconstrução sempre problemática e incompleta do que não existe mais. [...] a história [é] uma representação do passado." (NORA, p. 9, 1993). Portanto a memória é algo recuperável por princípio, construído junto ao presente e pelo presente.

Halbwachs (2004) contribui com a terminologia Memória Coletiva, isto é, aquela memória externa ao indivíduo. Ela está diretamente relacionada ao coletivo, porque a memória é parte de um processo social, no qual os indivíduos são vistos em coletivo, interagindo uns com os outros, ao longo de suas vidas e determinados por estruturas sociais (SANTOS, 2003). Por esta razão, de acordo com Halbwachs, os indivíduos se recordam apenas na sociedade que os reconhece, o que torna os eventos do passado em memórias do grupo. Tal conceito de memória diverge de Le Goff (2003), que considera a memória coletiva como pertencente às sociedades sem escritas, enquanto para o primeiro, memória coletiva e memória social são sinônimas. 


\section{SEMINÁRIO DE PESQUISA EM CIÊNCIAS HUMANAS - SEPECH \\ Humanidades, Estado e desafios didático-científicos \\ Londrina, 27 a 29 de julho de 2016}

\section{PARADIGMAS CUSTODIAL E PÓS-CUSTODIAL NAS UNIDADES DE INFORMAÇÃO}

Percebe-se, portanto, a memória como uma construção social e histórica, sendo um dos resultados dos processos de guarda e posterior disseminação, o que aproxima os paradigmas custodial e pós-custodial na Ciência da Informação.

Ao longo do tempo, as Unidades de Informação tinham maior preocupação com a guarda dos materiais de informação. No âmbito do Arquivo, temos uma necessidade dessa guarda como uma ação legitimadora ou por necessidade de prova. Desta forma,

a parte da visão de que, em um paradigma custodial, a guarda do documento possui primazia sobre o acesso, trazemos à discussão outros conceitos implícitos neste paradigma, sobretudo ligados ao patrimônio e ao primado da história como fonte legitimadora. (ROCKEMBACH, 2015, p. 103)

No âmbito na Biblioteca, e mesmo na área de estudo da Biblioteconomia, não foi diferente. Ação que pode ser percebida na antiguidade e mesmo no período medieval, a preocupação com o recolhimento do material, sua guarda e conservação. Isto é, o paradigma custodial era uma diretriz tanto na prática (Biblioteca) quanto na teoria (Biblioteconomia), assim

No tocante ao paradigma custodial, historicista, patrimonialista e tecnicista, a formação prática, recebida no espaço acadêmico e, sobretudo, no espaço institucional ou funcional das bibliotecas, arquivos e museus, apontava claramente para a sobrevalorização da custódia ou guarda, da conservação e do suporte. (SILVA, 2013, p. 20)

A guarda tinha como foco alguns materiais informacional tradicionais, como livros, documento arquivístico. Porém Paul Otlet lembrou, também, dos documentos tridimensionais (abarcando diversos materiais, como obras de arte, imagens fotográficas, e posteriormente películas cinematográficas, produções virtuais na web), ajudando a expandir a noção de documento, para além do seu suporte, e, também, a se preocupar com o acesso desses materiais, inicialmente entre as instituições, ajudando a desenvolver o paradigma pós-custodial, já que o

objetivo não era juntar uma coleção, guardar um estoque numa determinada instituição, mas sim promover um serviço transversal, cooperativo entre as diferentes instituições (e entre os diferentes tipos de instituições, também) (...). (ARAÚJO, 2014, p. 4-5)

SMIT (2003) também mostra essa nova abordagem, lembrando a tensão entre os conceitos de documento/informação, e como esses conceitos/materiais de informação, se relacionam nos arquivos e bibliotecas. Enquanto nos arquivos, como dito acima, o documento tem uma função de prova, já em uma biblioteca, a preocupação se dá à informação contida nos documentos.

Ainda, segundo Silva, 


\section{SEMINÁRIO DE PESQUISA EM CIÊNCIAS HUMANAS - SEPECH \\ Humanidades, Estado e desafios didático-científicos \\ Londrina, 27 a 29 de julho de 2016}

o paradigma emergente, pós-custodial, informacional e científico, postulado para a área da documentação/informação, surge associado à perspectiva evolutiva que anuncia como inevitável a emergência de uma Ciência da Informação(SILVA, 2013, p. 25)

Portanto, podemos dizer que os estudos sobre a função informacional nas Unidades de Informação, no tocante à memória, surgem com o desenvolvimento póscustodial.

\section{FUNÇÕES INFORMACIONAIS E ORGANIZAÇÃO DA MEMÓRIA}

Ao pensar na guarda e na difusão da memória na sociedade, precisa-se trazer algumas discussões importantes para a área da Ciência da Informação, como o processo de organização e classificação da informação e do conhecimento, uma das principais áreas de pesquisa e estudo na Ciência da Informação.

Primeiramente, resgata-se três tipos de difusão em arquivos, mas que pode se aplicar às Unidades de Informação:

a difusão educativa, que compreende uma relação entre a instituição arquivo e as escolas por meio de visitas e conhecimento dos documentos custodiados; a difusão editorial, que, por meio de publicações, divulgam os produtos e serviços do arquivo; e a difusão cultural, voltada para projetos culturais com diversas temáticas. (BELLOTTO, 2004 apud ROCKEMBACH, 2015, p. 104)

Mas para uma efetiva difusão dessa informação/memória nas Unidades de Informação, é imprescindível pensar na forma em como dispor os recursos informacionais e como facilitar a sua recuperação. Assim, Pombo (1988) fala das diversas formas de organização e classificação, e, especificamente, fala em quatro níveis de classificação: o primeiro nível, a classificação dos seres; o segundo nível, a classificação dos saberes; o terceiro nível, a classificação dos livros e o quarto nível, classificação das informações.

Para este trabalho, as classificações biblioteconômicas e documentais serão abordadas, já que elas têm "intuitos funcionais imediatos" (POMBO, 1988, p. 12), isto é, são classificações pragmáticas.

Cabe salientar que

após a explosão documental que se seguiu à segunda guerra mundial, quando os métodos tradicionais de documentação deixaram de fazer qualquer sentido, as classificações documentais e biblioteconômicas passarem a ser elaboradas tendo em vista, ainda nos anos quarenta, facilitar a automatização das relações entre as diversas classes de documentos e, a partir dos anos setenta, permitir decididamente a informatização eletrônica do processo documental. (POMBO, 1988, p. 12-13)

Dodebei faz uma interessante aproximação entre informação e memória, quando defende que 


\section{SEMINÁRIO DE PESQUISA EM CIÊNCIAS HUMANAS - SEPECH \\ Humanidades, Estado e desafios didático-científicos \\ Londrina, 27 a 29 de julho de 2016}

Informação e Memória são a face material da economia representada pelo consumo de bens que transitam nas redes sociais ubíquas e, ao mesmo tempo, a face material dos percursos da valorização de bens culturais e da preservação de patrimônios. (DODEBEI, 2010, p. 59)

Isso faz pensar em algumas questões a respeito da utilização de procedimentos de classificação e organização documental, visando a recuperação posterior da informação/memória, que permitirão maior eficiência e eficácia para as funções informacionais dos materiais de memória disponíveis, isto é, uma dessas funções, a disseminação, se relaciona com uma outra área de estudo na Ciência da Informação, a satisfação das necessidades informacionais, estudadas em Comportamento Informacional.

Assim, como foi visto, a disseminação torna-se um importante momento para o tema da memória, justificando um cuidado maior no momento do registro, seleção/aquisição e organização/classificação.

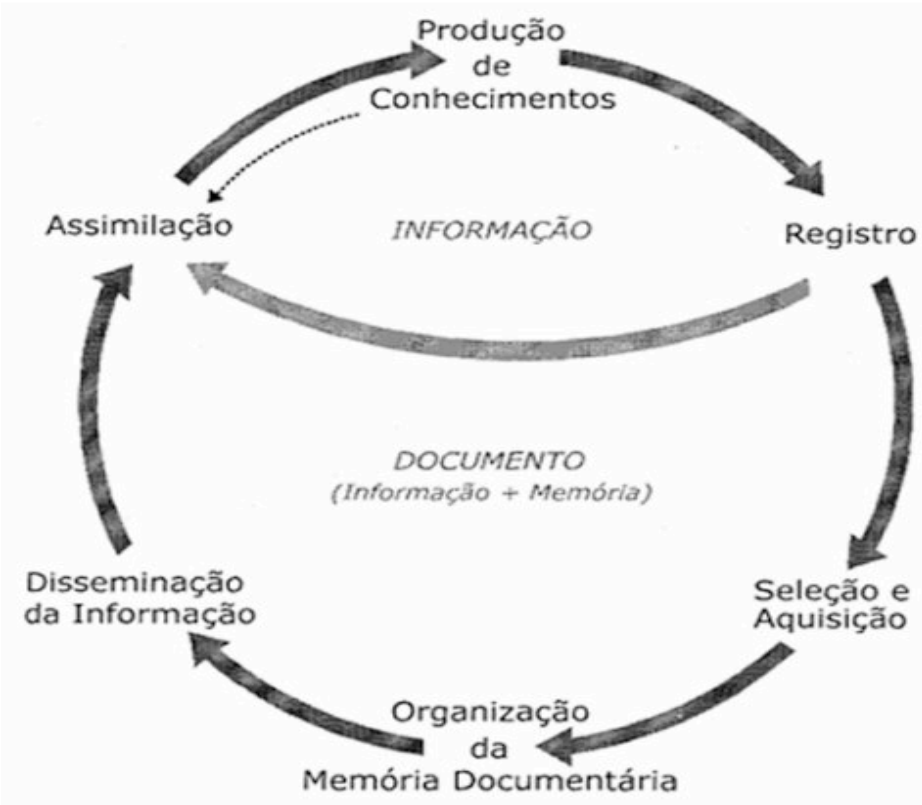

Figura 1: Ciclo da Informação

Fonte: Dodebei, 2010, p. 62

$\mathrm{Na}$ figura acima, são demonstrados dois ciclos, um maior, tradicional, no qual a Ciência da Informação contribuiu para o estudo da memória, onde ela é selecionada, tratada e, posteriormente, disseminada. Já o ciclo menor, a memória/informação é produzida e disponibilizada, dificultando o trabalho de recuperação.

Afinal, assistiu-se recentemente, a uma segunda onda de explosão informacional, onde a informação na web também assume uma função de memória, onde os processos de aquisição/seleção e organização (visando à disseminação) não seguem o momento da produção e registro da informação, sendo consumida em sua forma bruta, sem o devido tratamento.

Começa-se, então, a delinear um campo interdisciplinar de estudo, no qual a Ciência da Informação, Filosofia, Ciências Humanas e a Informática podem trabalhar 


\section{SEMINÁRIO DE PESQUISA EM CIÊNCIAS HUMANAS - SEPECH \\ Humanidades, Estado e desafios didático-científicos \\ Londrina, 27 a 29 de julho de 2016}

em conjunto, onde a memória possa ser devidamente selecionada e recuperada, conforme a necessidade do usuário e independente da Unidade de Informação, já que este usuário

não sente uma 'necessidade arquivística', ou uma 'necessidade biblioteconômica' ou uma 'necessidade museológica' - ainda que, para resolver seu problema, muitas vezes ele precise escolher entre se dirigir a um arquivo, a uma biblioteca ou a um museu. (ARAÚJO, 2013, p. 233)

Portanto, é papel das Unidades de Informação, enquanto lugares de memória, suprir essas necessidades, graças ao trabalho do cientista da informação e dos profissionais envolvidos no ciclo da informação, onde a memória se insere.

\section{CONSIDERAÇÕES FINAIS}

$\mathrm{O}$ artigo mostrou a função informacional da memória no contexto das Unidades de Informação. Ela, a memória, tem um caráter interdisciplinar quando tratada como informação, que é o ponto de convergência interdisciplinar para as bibliotecas, os museus e os arquivos; mas também tem outras formas de abordagem, de acordo com as diversas áreas do conhecimento e pesquisa, como Ciência da Computação, Ciências Humanas, como Filosofia, Sociologia, História e outras.

As Unidades de Informação têm funções informacionais, como a guarda, o tratamento e a disseminação dos materiais de informação, as quais acompanharam o crescimento da Ciência da Informação. Essas funções existem pois os locais de informação são utilizados para lembrar eventos, lugares, pessoas e servem como evidências do passado. Desta forma alcançando uma abordagem pós-custodial, o que propiciou o desenvolvimento e recuperação da memória como informação tangível dentro das bibliotecas, museus e arquivos.

Portanto, ao se pensar sobre a função informacional da Unidade de Informação, para a sua efetiva realização, tem-se que pensar em alguns pontos, como: o tipo de memória que irá ser trabalhada, a organização para a sua devida recuperação e disseminação e as necessidades dos usuários que estarão presentes nesse contexto.

\section{REFERÊNCIAS}

ARAÚJO, C. A. A. A perspectiva de estudos sobre os sujeitos na Arquivologia, na Biblioteconomia e na Museologia. Em Questão, Porto Alegre, v. 19, n.1, p. 213-238, jan./jun. 2013.

C. A. A. O que é Ciência da Informação?. Informação \& Informação, Londrina, v. 19, n. 1, p. 01-30, jan./abri. 2014. Disponível em: $<$ http://www.uel.br/revistas/uel/index.php/informacao/article/view/15958>. Acesso em: 20 abri. 2016.

BUCKLAND, M. K. Information as thing. Journal of the American Society for 
Information Science (JASIS), v.45, n.5, p.351-360, 1991.

DODEBEI, V. Memória e informação - interações no campo de pesquisa. In: MARANON, E. I. M. (org.) MEMÓRIA: um lugar de diálogo para arquivos, bibliotecas e museus. São Carlos: Compacta Gráfica e Editora, 2010.

HALBWACHS, M. A memória coletiva. São Paulo: Centauro Editora, 2004.

HOLANDA, A. B. Memória e esquecimento na Ciência da Informação: um estudo exploratório, 2011. Dissertação (Mestrado em Ciência da Informação) - Centro de Artes e Comuniação, Universidade Federal de Pernambuco, Recife. 2011.

MURGUIA, E. I. Apresentação. In: MARANON, E. I. M. (org.) MEMÓRIA: um lugar de diálogo para arquivos, bibliotecas e museus. São Carlos: Compacta Gráfica e Editora, 2010.

LE GOFF, J. História e memória: escrita e literatura. Campinas: Editora da Unicamp, 2003.

NORA, P. Entre memória e história: a problemática dos lugares. Projeto História. São Paulo, n. 10, p. 7-28, dez. 1993.

POMBO, O. Da classificação dos seres à classificação dos saberes. Revista da Biblioteca Nacional de Lisboa, Lisboa, n. 2, p. 19-33, primavera, 1988.

, O. Epistemologia da interdisciplinaridade. In: SEMINÁRIO INTERNACIONAL INTERDISCIPLINARIDADE, HUMANISMO, UNIVERSIDADE. 2003. Anais... Porto: Universidade do Porto, 2003. p. 1-18. (Cátedra Humanismo Latino). Disponível em: $<$ http://www.uesc.br/cpa/artigos/epistemologia_interdidciplinaridade.pdf $>$. Acesso em: 20 fev. 2016.

ROCKEMBACH, M. Difusão em arquivos: uma função arquivística, infor-macional e comunicacional. Informação Arquivística, Rio de Janeiro, v. 4, n. 1, p. 98-118, jan./jun., 2015

SANTOS, M. S. dos. Memória coletiva e teoria social. São Paulo: Annablume, 2003.

SARACEVIC, T. Interdisciplinarity nature of Information Science. Ciência da $\begin{array}{lllll}\text { Informação, } & \text { Brasília, } & \text { v.24, } & \text { n.1, } & \text { p.36-41, }\end{array}$

SILVA, A. M. A transição paradigmática e o posicionamento da museologia face à Ciência da Informação transdisciplinar. In: ZENY, D. (org). Arquivos, Bibliotecas e Museus: realidades de Portugal e Brasil. Salvador: EDUFBA, 2013

SILVA, K. V; SILVA, M. H. Dicionário de conceitos históricos. São Paulo: Contexto, 2009. 


\section{SEMINÁRIO DE PESQUISA EM CIÊNCIAS HUMANAS - SEPECH \\ Humanidades, Estado e desafios didático-científicos \\ Londrina, 27 a 29 de julho de 2016}

SMIT, J. W. Arquivologia/Biblioteconomia: interfaces das Ciências da Informação. Informação e Informação. Londrina, v. 8, n.1, jun./dez. 2003. Disponível em $<$ http://www.uel.br/revistas/uel/index.php/informacao/article/view/1713/1464>. Acesso em 19 abr. 2016. 